\title{
CINEMA EDUCATIVO: UMA ABORDAGEM HISTÓRICA
}

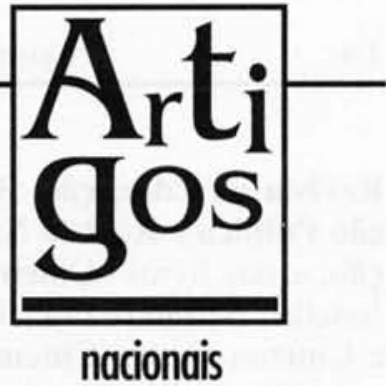

\section{O cinema aplicado à educação fez parte da experiência cinematográfica brasileira na década de 20; posteriormente, com a fundação em 1936 do INCE - Instituto Nacional de Cinema Educativo, deixou diversificada produção}

Os professores dispõem, cada vez mais, de novas tecnologias audiovisuais que podem ser incorporadas à sua prática escolar. Vídeos e computadores, com os seus recursos de multimídia, fazem parte de um verdadeiro arsenal ainda pouco explorado em sala de aula. Estas novidades nos apresentam um universo quase desconhecido, diante do qual, não raro, demonstramos nossa perplexidade. Afinal de contas, tratase não apenas de introduzir uma nova tecnologia, mas sim de pensá-la dentro de uma linha de ação pedagógica. Neste sentido, vale lembrar que este problema não é propriamente novo ou exclusivo dos anos 90 e que, dentro da educação brasileira, ele remonta às primeiras décadas deste século. Referimo-nos basicamente à experiência do cinema educativo.

O cinema educativo, entendido como um importante auxiliar do professor no ensino e um poderoso instrumento de atuação sobre o social, foi debatido e defendido por muitos pedagogos e intelectuais paulistas e cariocas nos anos 20 e 30 , como Manuel Bergstrom Lourenço Filho, Fernando de Azevedo, Edgar Roquete Pinto e Jonathas Serrano, entre outros, que também estavam preocupados com a introdução dos princípios da chamada Escola Nova nos currículos. Ao lado dos aplausos às primeiras iniciativas dos governos estadual e federal pelo "bom" cinema, uma verdadeira campanha seria desenvolvida nas revistas pedagógicas oficiais $^{1}$, como Educação, Escola Nova,

\section{O AUTOR}

Eduardo Victorio Morettin

Mestre em Artes pela Escola de Comunicações da Universidade de São Paulo. Professor da Universidade Paulista (UNIP) e do Colégio Anglo Brasileiro.

1. A revista Educação foi editada sob a responsabilidade da Diretoria Geral da Instrução Pública e da Sociedade de Educação do Estado de São Paulo e circulou de 1927 a 1930, em substituição a um outro periódico oficial, a Revista Escolar. Em 1930. Educação passa por uma reformulação e ganha novo título: Escola Nova; a partir de então é editada apenas pela Diretoria Geral da Instrução Pública do Estado de São Paulo. No final de 1931 ela volta a circular com o antigo nome, Educação.

O Boletim da Educação Pública circulou a partir de 1930 e era órgão da Diretoria Geral da Instrução Pública do Distrito Federal.

A Revista Nacional de Educação circulou de 1932 a 1934 sob a responsabilidade do Ministério da Educação e Saúde Pública.

Ver mais sobre o assunto em: MORETTIN,Eduardo Victorio. Cinema e História: Uma análise do filme "Os Bandeirantes". São Paulo: ECA-USP, 1994. Dissertação de Mestrado. (N.E.) 
Revista de Educação, Boletim da Educação Pública e Revista Nacional de Educação, e nos livros ${ }^{2}$ Cinema e Educação, de Jonathas Serrano e Francisco Venâncio Filho e Cinema contra Cinema, de Joaquim Canuto Mendes de Almeida, ambos de 1931.

O cinema educativo foi apoiado na época pelas revistas especializadas em cinema, como Cinearte, que acolheram em suas páginas os autores de Cinema e Educação, contribuindo para a divulgação das suas idéias. A preocupação ética e moral dos educadores um dos temas do projeto que abordaremos a seguir - ia ao encontro da procura de "seriedade" que estes críticos queriam dar ao cinema brasileiro, a fim de aumentar a sua aceitação no restante da sociedade.

\section{CINEMA PARA O BEM, CONTRA O MAL}

Um dos primeiros educadores a abordar a relação entre cinema e moral no Brasil foi Lourenço Filho, que, em 1927, procura mostrar a maneira pela qual o cinema pode interferir negativamente na formação moral dos jovens ${ }^{3}$. Para ele, o "problema moral" - "o alpha e o omega de todo labor educativo" - é uma questão social, na medida em que as influências negativas podem romper o equilíbrio estável existente na conciliação entre os interesses particulares - campo de incidência moral - e os gerais. Assim, os abalos na formação do indivíduo poderiam desestruturar o tecido social. É com preocupação que o educador, futuro diretor da Instrução Pública do Estado de São Paulo, nota o surgimento de "pequenas organizações criminosas de meninos, de São Paulo como no interior do Estado, todas ellas inspiradas no exemplo vivo do cinematographo".

Dentro desta linha de pensamento, encontramos afirmações como a de Canuto Mendes de Almeida, para quem até mesmo as "obras primas" feitas sobre uma base moral questionável deviam ser censuradas. Para ele, no que diz respeito ao cinema, "a açcão educativa sobre as fitas por mim preconizadas não se vai exercer contra uma arte. O cinema, hoje, antes de ser uma arte está convertido num negocio. Impõe-se a regularisação desse negocio quanto é licita a intervenção dos poderes publicos no commercio dos entorpecentes, com os devidos descontos" 4 .

Apesar do "perigo" representado pelo cinema, haveria uma possibilidade de salvá-lo, ou melhor, de livrar os indefesos espectadores da "má sugestão" causada pela sétima arte. Estamos falando do seu aproveitamento para fins educativos. Este raciocínio aparece, por exemplo, no já citado Cinema e Educação, onde os autores acreditam que o novo meio de comunicação poderia ser utilizado tanto para o "bem" como para o "mal".

O cinema identificado com o mal é o "cine-drama". Este tipo de cinema corresponderia a uma fase, presente desde sua criação, que seria substituída pelo cinema educativo $^{5}$. Para os autores, a grande maio-

2. ALMEIDA, Joaquim Canuto Mendes de. Cinema contra cinema: bases gerais para um esboço de organização de cinema educativo no Brasil. São Paulo: São Paulo Ed., 1931.

SERRANO, Jonathas e VENÂNCIO FILHO, Francisco. Cinema e educação. São Paulo e Rio de Janeiro: Caieiras e MeIhoramentos, 1931.

3. LOURENÇO FILHO. A moral no theatro, principalmente no cinematógrapho. Educação. São Paulo, II (3): 227-234, mar. 1928. Este artigo foi apresentado em dezembro de 1927 no V Congresso Americano da Criança, realizado em Havana. Optamos por manter a grafia de época nos textos citados.

4. ALMEIDA. J. Canuto Mendes de. Cinema de Estado? Educação. São Paulo, IV (1-2): 141, ago-set, 1931, grifos do autor.

5. O livro de Canuto Mendes de Almeida, Cinema contra cinema, possui uma argumentação muito parecida, como é salientado no prefácio de Lourenço Filho. Para ele, a "cura" do cinema deseducativo é o cinema educativo, orientado para o bem (Cf. Canuto M. de Almeida, op. cit., p. 5). 
ria das produções de então provocam o "riso" e "arranhões" na moral. O alvo de sua critíca é a maioria das comédias, dramas e filmes policiais, com raríssimas exceções.

Ao traçarem um panorama desalentador da produção educativa nacional e conclamarem os educadores a participar da campanha em prol do "bom" cinema, Jonathas Serrano e Venâncio Filho sintetizam algumas das carcterísticas morais que o filme educativo deveria conter: "urge produzir, propagar, amparar por todas as formas o filme capaz de distrair sem causar damnos moraes, o filme de emoção sadia, não piégas, sem ridiculez, mas humano, patriótico, superiormente social. Propugnemos o filme brasileiro, sem exaggerações, documental, de observação exacta, serena, sem legendas pedantes, sem namoros risíveis nem scenas de mundo equivoco em ambientes indesejaveis".

Para estes educadores, as pessoas deveriam ter uma relação com o filme marcada pelo raciocínio frio e abstrato e não mais pelo sentimento. Um público que, entendido como um todo homogêneo, não seria capaz de agir racionalmente diante da influência negativa do cinema. Eles pensavam, em particular, nas crianças. Seria o "cine-drama" o responsável por certas manifestações descontroladas que, costumeiramente, ocorriam durante as "matinées infantis: a gritaria ensurdecedora da sala, a exaltação desvairada dos garotos, presos de intensa emoção".

A disciplinarização deveria ser imposta, pois somente assim seria possível o cinema educativo incutir nas crianças o "valor do trabalho e da solidariedade". Obviamente, o aluno aqui é visto como um receptáculo vazio, pronto para receber os "bons" ensinamentos e amoldar-se àquilo que a "sociedade" dele espera.

É bom salientar que a crítica de cunho moral no Brasil não se iniciou com estes pedagogos. No entanto, o dado novo nesta crí- tica foi que ela constitui o produto do trabalho de um grupo de intelectuais que, através de um projeto, ocupou-se dessa questão como sendo de interesse comum à sociedade. Para que a "grande cruzada" se colocasse em marcha era necessário o apoio de todos: o oriundo da "iniciativa particular" aliado à "acção da imprensa [e] a colaboração da própria Igreja Catholica" e, principalmente, o "official".

O espaço conseguido nas publicações oficiais acima citadas indicava que o Estado não estava surdo às reclamações vindas dos educadores. Mapeada a área a ser penetrada e apontados os perigos, era necessária, no entanto, uma ação de maior envergadura. A presença do Estado, solicitada por quase todos os intelectuais preocupados com a questão, foi colocada como condição sine qua non para o sucesso da empreitada. Antes mesmo do movimento de outubro de 1930 , ele seria instado a intervir na censura dos filmes, apoiar o trabalho dos educadores e até a produzir filmes.

Em 1927, Lourenço Filho, no artigo mencionado, já reclamava uma maior fiscalização do cinema a fim de evitar a sua ação enquanto "um factor de corrupção moral, anarchisador da mente e do carater infantil".

Existem, antes de 1932, ano em que o serviço de censura foi nacionalizado pelo governo provisório de Getúlio Vargas, tentativas frustadas de um maior controle dos poderes instituídos sobre a produção cinematográfica.

O decreto $\mathrm{n}^{\circ} 18.527$ de 10 de dezembro de 1928 regulamentou a censura cinematográfica no Brasil, que ficava sob os cuidados do Ministério do Interior e da Justiça, cabendo aos chefes de polícia locais a vigilância pelo bom cumprimento das suas disposições.

Tudo leva a crer que esta lei - usada para coibir os curtas-metragem que retratavam acontecimentos políticos e, involuntariamente, a nossa precária situação social - 
não atendia aos interesses destes pedagogos, em função da própria existência de uma grande quantidade de artigos publicados nas revistas pedagógicas oficiais solicitando uma censura mais atuante, no período imediatamente posterior à sua promulgação, como indicamos acima. A constante e forte crítica de cunho moral presente nestes textos leva necessariamente à constatação de que o Estado não se fazia presente como deveria. Além de estes artigos criticarem veladamente a legislação vigente, apontam para a insuficiência das iniciativas particulares ou mesmo questionam a autoridade dos pais no que diz respeito à educação de seus filhos ${ }^{6}$.

Para estes educadores, a censura deveria adquirir um caráter "cultural", não sendo mais cuidada pela polícia local. Com efeito, em 1932, o serviço de censura foi nacionalizado. A sua intervenção deveria ter "um cunho acentuadamente cultural", ficando sob a alçada do Ministério da Educação e Saúde Pública.

Na exposição de motivos do decreto que regulamentou a censura, os filmes educativos são destacados como um valoroso "material de ensino, visto permitirem assistencia cultural, com vantagens especiais de atuação direta sobre as grandes massas populares e, mesmo, sobre analfabetos" 7 .

Este decreto representou uma resposta aos anseios dos educadores preocupados com o cinema educativo, pois, entre outros dispositivos, criou uma Comissão de Censura, da qual faziam parte, entre outros, Edgar Roquete Pinto, nomeado posteriormente seu presidente, e Jonathas Serrano, profes- sor designado pelo Ministério da Educação. $\mathrm{O}$ decreto também definiu filme educativo, utilizando-o como um dos critérios classificadores do material selecionado ${ }^{8}$. Cabe destacar que um outro artigo previa a inclusão obrigatória, na programação dos cinemas, de um filme considerado educativo pela Comissão de Censura.

\section{APOIO OFICIAL E LARGA PRODUÇÃO}

No dia 3 de janeiro de 1933, o Convênio Cinematográfico Educativo foi aberto com um discurso de Roquete Pinto. Nele, o presidente da Comissão de Censura Cinematográfica, após um breve relatório dos trabalhos já realizados, aponta para uma nova função, tida por prioritária e muito citada nos anos posteriores, do cinema e do rádio: a de serem "escolas dos que não têm escolas", pois eles "vão aos que não sabem ler", constituindo-se, por vezes, no único meio de transmissão da arte, da ciência e da técnica.

O movimento pelo cinema educativo sofre, no entanto, um revés com a criação do Departamento de Propaganda e Difusão Cultural (DPDC), em 1934, subordinado ao Ministério da Justiça e dos Negócios Interiores. A censura cinematográfica foi retirada da órbita de influência do Ministério da Educação. Este instituto deu origem ao Departamento de Imprensa e Propaganda (DIP), criado em 1939 para coordenar sozinho toda a área de comunicação do Estado Novo. No que diz respeito ao cinema, o DIP, vinculado diretamente ao presidente da $\mathrm{Re}$ pública, consolidou a intervenção do Estado na área cinematográfica, censurando, fo-

6. Cf. Jonathas Serrano. O cinema educativo no Distrito Federal. Boletim da Educação Pública. I (2): 188, abr.-jun. 1930, e Carlos Magalhães Lebeis, Cinema e censura. Revista Nacional de Educação (1): 35-38, out. 1932.

7. Decreto n'21240 - de 4 de abril de 1932. Revista Nacional de Educação (1): 4-16, out. 1932.

8. Os filmes educativos seriam não só os "que tenham por objeto intencional divulgar conhecimentos científicos, como aqueles cujo entrecho musical ou figurado se desenvolver em torno de motivos artísticos, tendentes a revelar ao público os grandes aspectos da natureza ou da cultura". (Cf. Decreto n० 21240 — de 4 de abril de 1932. Revista Nacional de Educação (1): 6, out. 1932). 
mentando o cinema nacional, cobrando taxas, fiscalizando a exibição e produzindo filmes?.

Apesar desse revés, o movimento pelo cinema educativo obteve uma grande vitória com a criação, em 1936, em caráter não oficial, do Instituto Nacional de Cinema Educativo (INCE). O Instituto representou de fato a concretização do projeto, através da proposta de uma produção contínua de filmes, pela primeira vez encetada pelo Estado.

Contando com o apoio oficial, Roquete Pinto, designado diretor-presidente, procurou reorganizar e sistematizar o movimento, a fim de se aproveitar o impulso considerado definitivo.

Em março, o INCE iniciou as suas atividades, sendo contratado como diretor-técnico Humberto Mauro, um dos mais importantes cineastas da época, autor de filmes como Sangue Mineiro, 1930, e Ganga Bruta, 1933. Em maio do mesmo ano foram apresentados os primeiros filmes editados, e Preparo da Vacina contra a Raiva estreou no mês seguinte no Palácio Teatro da então Capital Federal, dando início a uma série de filmes educativos populares, ou seja, feitos em $35 \mathrm{~mm}$ e destinados à exibição pública. Em 7 de setembro, o INCE produziu Dia da Pátria, seu primeiro filme sonoro de tamanho escolar, isto é, produzido em $16 \mathrm{~mm}$ e reservado para a projeção em sala de aula e institutos de cultura.

As atividades do INCE não se limitavam apenas à produção de filmes. O Instituto se propunha a manter-se informado sobre os filmes educativos existentes e disponíveis e as escolas que mantinham projetores. Além disso, a formação de uma biblioteca especializada e a publicação de uma revista do Instituto revelavam a intenção de sistematizar as informações dispersas, bem como a de coordenar o movimento. O Instituto tinha contato com as entidades congêneres existentes na Europa, através das viagens de seu diretor-presidente e do próprio Mauro à Itália, França e Alemanha.

No dia 13 de janeiro de 1937, o governo regularizou as atividades do INCE por meio de uma lei que fundou outras entidades, como o Serviço do Patrimônio Histórico e Artístico Nacional e o Museu Nacional de Belas Artes, entre outros.

De 1936 até 1940, o INCE produziu uma série de reportagens sobre eventos cívicos como Dia da Bandeira, Dia da Pátria, além de outras manifestações de exaltação à pátria como Juramento à Bandeira, de 1937, Hino à Vitória, de 1938, Parada da Mocidade, de 1939, e Parada da Juventude, de $1940^{10}$.

De certa forma, estas produções, pela própria temática, avançaram no campo de atuação do DIP, o que contribuiu para reativar antigos atritos. Entende-se desta forma a ausência daquele tipo de reportagem cívica nos anos de 1941 a 1945 entre as produções do Instituto. Podemos supor que as pressões oriundas do DIP tivessem surtido efeito, restringindo a área de inserção do INCE apenas aos temas relacionados à educação propriamente dita, como zoologia, educação artística, física, literatura, dança, geografia e história, por exemplo, presentes em seus filmes desde o primeiro ano de sua fundação.

Em relação a estes últimos assuntos, Humberto Mauro sempre contou com a assessoria de especialistas, como Carlos Chagas Filho, Vital Brasil, Agnaldo Alves Filho (Instituto Pasteur), Alírio de Matos (Observatório Nacional) e Afonso de Taunay (Museu Paulista). Esta orientação dada por es-

9. GOULART, Silvana. Sob a verdade oficial: ideologia, propaganda e censura no Estado Novo. São Paulo: Marco Zero; Brasília: MCT/CNPq, 1990. p. 50-52.

10. Cf. SOUZA, Carlos Roberto de. Catálogo - Filmes produzidos pelo INCE. Rio de Janeiro: Fundação Cinema Brasileiro, 1990. 
pecialistas a Mauro constituía um dos pontos fundamentais do projeto, assegurado pelo projeto de lei de 1937 que criou o INCE. A participação destes intelectuais garantiria a apresentação das noções tidas como verdadeiras, a elaboração de um texto "correto" do ponto de vista científico e a sua "boa" adequação ao ensino.

\section{A "VERDADE" NO CINEMA/EDUCAÇÃO}

O que vem a ser "correto" cientificamente e "bem" apropriado à sala de aula pode ser medido pela concepção que estes educadores tinham do ensino de história através do cinema.

As diretrizes que norteariam os professores interessados nesta área foram esboçadas em um artigo de Sud Menucci, de 1929. Para ele, o principal problema no aprendizado do passado através do cinema recaía na dificuldade de preservação da "objetividade" histórica. Apesar disso, o autor acredita na recomposição cinematográfica de uma época, ressaltando, porém, que "as reconstruções que eu imagino não se parecem com as que andam por ahi pelas casas de diversões em que a paixão é sempre apresentada como nível de todas as acções e em que as personagens principais são de regra figuras apagadas da história ou às vezes gente que não existiu, mas de que o enredo precisava para manter vivo o fogo sagrado do reclamo"11.

A busca da fidelidade ao passado levou estes educadores a criticarem os filmes que recorriam à história como pretexto para dar vazão a sentimentos pouco condizentes com o saber científico. É por isso que os educadores descartavam este tipo de produção, identificada como "romance histórico", ou seja, filmes onde "há sempre larga porção de fantasia, em que não é possível marcar a linha divisória da realidade"12.
Dentro desta proposta de representação fílmica do passado herdada do positivismo, em 1940 o INCE produz o seu primeiro filme de reconstituição histórica intitulado $O s$ Bandeirantes. Este média -metragem teve a orientação geral de Roquete Pinto e a coordenação histórica de Afonso de Taunay, com a direção de Humberto Mauro.

O filme aborda o processo de subordinação da "natureza" ao homem. Este processo, no entanto, situa-se em um tempo e em um espaço muito bem definidos: o Brasil colonial dos séculos XVI e XVII. Em função dessa historicidade, duas considerações devem ser feitas. Em primeiro lugar, não é o homem em geral, mas sim o homem de origem européia o responsável pela introdução da civilização. Por último, este processo está relacionado com o da construção da nacionalidade. Assim, procura-se definir a contribuição dada por cada segmento racial, destacando a importância de alguns heróis, como José de Anchieta, Antônio Raposo Tavares e Fernão Dias Pais, que são trabalhados de maneira mítica.

Neste filme, que se pretende "objetivo" $\mathrm{e}$ "científico", a escravização e o genocídio do índio são simplesmente omitidos, afora idealizar a relação entre o colonizador e o colonizado, destacando como qualidades positivas a submissão e a obediência ao branco. Além disso, os bandeirantes aparecem como pessoas que se sacrificam pelo todo, sem nenhum interesse material nas expedições que empreendem pelo Interior da Colônia. Se Fernão Dias procura ouro, é para que Portugal se enriqueça. 
É este, para o INCE, o "verdadeiro filme histórico", ou seja, aquele que reproduz de maneira "fiel" os fatos ocorridos no passado, recorrendo a um especialista no assunto, como é o caso de Taunay, "historiador das bandeiras" e "membro da Academia Brasileira de Letras", como anuncia o locutor na primeira imagem do filme, que é justamente a do diretor do Museu Paulista. Além disso, enquanto filme "científico", apresenta os "documentos" utilizados na confecção da película - mapas, quadros, maquetes e esculturas - bem como as instituições que os forneceram.

Com certeza, Os Bandeirantes não provocam os "arranhões" na moral que tanto irritavam os educadores. Também a sua ação não serve de pano de fundo para "namoros risíveis" e "paixões" pouco condizentes com a "verdade histórica".

No entanto, e aí reside um dos principais motivos do fracasso deste projeto, o filme não consegue edificar uma imagem grandiosa da ação bandeirante. Entre outras coisas, é arrastado, lento e sem dinamismo, feito de acordo com as expectativas do que seria um bom cinema do ponto de vista destes intelectuais, mas não do aluno.

Refletir sobre a utilização do cinema aplicado ao ensino de história deve levar em consideração estas questões, para que possamos, de fato, incluir o filme na prática escolar, tornando-o, sem dúvida, um instrumento de conhecimento do nosso passado, mas, principalmente, um meio de discutirmos melhor o momento em que ele foi produzido. Da mesma forma que em Os Bandeirantes o presente ao qual se relaciona emerge - o

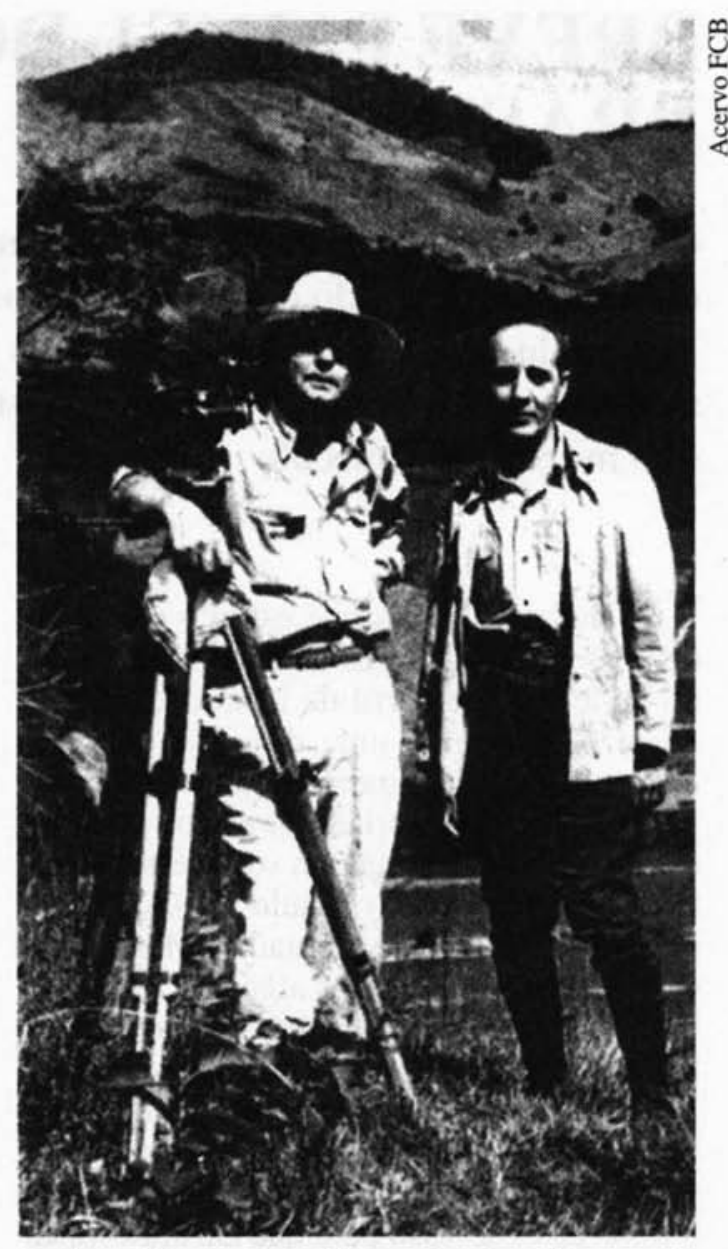

Humberto Mauro e Pasqual Leme, durante as filmagens de Rui Barbosa, 1949

bandeirante/presidente Vargas que se sacrifica pela colônia/Brasil -, Carlota Joaquina, de Carla Camurati, diz muito mais sobre as idas e vindas do país nos últimos anos do que sobre o impacto causado pela chegada da família real em 1808 em sua antiga Colônia. 